\title{
New technologies for marine research: five years of glider activities at IMEDEA
}

\author{
SIMÓN RUIZ ${ }^{1}$, BARTOLOMÉ GARAU ${ }^{2}$, MIGUEL MARTÍNEZ-LEDESMA ${ }^{1}$, \\ BENJAMÍN CASAS ${ }^{1}$, ANANDA PASCUAL ${ }^{1}$, GUILLERMO VIZOSO ${ }^{1}$ \\ JÉRÔME BOUFFARD ${ }^{1}$, EMMA HESLOP ${ }^{1}$, ALBERTO ALVAREZ ${ }^{1,3}$, PIERRE TESTOR ${ }^{4}$ \\ and JOAQUÍN TINTORÉ ${ }^{1,2}$
}

${ }^{1}$ IMEDEA (CSIC-UIB), Department of Marine Technologies, Operational Oceanography and Sustainability (TMOOS), Carrer Miquel Marquès 21,07190 Esporles, Spain. E-mail: simon.ruiz@uib.es

${ }^{2}$ SOCIB, Parc Bit, Naorte, Bloc A, 2a p. pta. 3, 07121 Palma de Mallorca, Spain.

${ }^{3}$ Present address: NURC, La Spezia, Italy.

${ }^{4}$ LOCEAN, 4 Place Jussieu, 75252 Paris cedex 05, France.

SUMMARY: This paper summarizes the glider activities carried out in the last 5 years by the IMEDEA Department of Marine Technologies, Operational Oceanography and Sustainability (TMOOS). TMOOS has been operating gliders in the Western Mediterranean Sea since 2006 and has set-up electronic and maintenance laboratories in order to establish a key glider port in the area. Twenty-two glider missions have been performed to date and over 17000 hydrographic and biogeochemical profiles collected. TMOOS is using gliders for operational, technological and scientific objectives. Studies of path planning analysis and adaptive sampling for gliders in combination with other platforms have been undertaken and new methodologies have been developed to process data from gliders. Thus far, IMEDEA gliders have contributed to the better understanding of mesoscale processes in the upper ocean, including the coupling between the physical and biogeochemical process of the marine ecosystem and, in combination with remote sensing observations, high-resolution glider data has enabled advances in new methodologies to improve coastal altimetry. Gliders have also proved to be important platforms for the development of operational oceanography tools and useful vehicles on which to test and implement new sensors for ocean monitoring.

Keywords: Autonomous underwater vehicles, ocean observing system, upper ocean mesoscale processes, Balearic Sea.

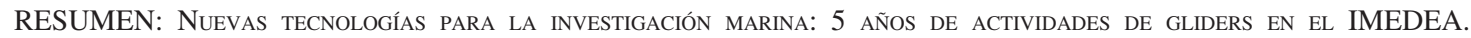
- Este artículo resume las actividades de gliders llevadas a cabo en los últimos 5 años en el Departamento de Tecnologías Marinas, Oceanografía Operacional y Sostenibilidad (TMOOS) del IMEDEA. El departamento TMOOS realiza misiones con gliders en el Mediterráneo occidental desde el año 2006. Se han creado nuevos laboratorios de electrónica y de mantenimiento con el fin de establecer un 'glider-port' clave en esta zona del Mediterráneo. Se han realizado veintidos misiones que han supuesto la adquisición de un total de 17.000 perfiles hidrográficos y biogeoquímicos. El TMOOS usa los planeadores submarinos con fines operacionales, tecnológicos y científicos. Se han realizado estudios sobre planificación de rutas y muestreo adaptativo de gliders en combinación con otras plataformas y se han desarrollado nuevas metodologías para el procesado de los datos. Los planeadores han contribuido a una mejor comprensión de los procesos de mesoescala de la capa superficial del océano, incluyendo el acoplamiento de procesos físicos y bio-geoquímicos de los ecosistemas marinos. Combinando observaciones de alta resolución de gliders y de satélites se ha avanzado en el desarrollo de nuevas metodologías para mejorar la altimetría costera. Además, los planeadores también han demostrado ser una plataforma ideal para la oceanografía operacional y en la que se pueden probar e implementar nuevos sensores para la monitorización de los océanos.

Palabras clave: vehículos autónomos submarinos, sistemas observación océano, procesos mesoescala capa superficial, mar Balear. 


\section{INTRODUCTION}

\section{Gliders as a new component for ocean observing systems}

Gliders are small, autonomous, buoyancy-driven vehicles designed to sample the upper ocean (Stommel 1989). They allow the autonomous and sustained collection of conductivity-temperature-depth (CTD) and biogeochemical measurements (e.g. fluorescence, oxygen and turbidity), at a higher spatial resolution and lower cost than conventional methods. Sensors such as acoustic transducers for the acquisition of velocity measurements have also been tested on gliders (Siegel 2009). At present, commercially available gliders can operate between the ocean surface and $1000 \mathrm{~m}$ depth (shallow units to $200 \mathrm{~m}$ ), but further research is ongoing to develop a prototype able to dive to $6000 \mathrm{~m}$ depth (Eriksen 2010).

By modifying their buoyancy and making use of small fins, gliders sample the water column describing a zigzag trajectory between the surface and deep levels, with a horizontal speed of 25 to $40 \mathrm{~cm} \mathrm{~s}^{-1}$. At every surfacing point gliders transmit data to a land station through bi-directional Iridium satellite communication, normally every 6 hours. At the surface gliders behaviour can be modified (e.g. sampling frequency, up/ down data acquisition and depth of inflexions) and the missions' waypoints can be changed. Autonomy at sea ranges from months to weeks, depending on the type of batteries (lithium or alkaline) and the glider mission configuration. Further details of technical/engineering characteristics and functioning of the three main classes of gliders used at present can be found in Webb et al. (2001), Sherman et al. (2001) and Eriksen et al. (2001).

Gliders are being implemented in ocean observing systems around the world (Fig. 1) and are already contributing to our knowledge of areas with few in-situ observations such as boundary currents (Testor et al. 2009). Rudnick et al. (2004) showed preliminary results on the use of gliders along the west coast of the United States of America (USA), where they were deployed to sample the continental shelf edge of the Washington coast (example of long-autonomy of an individual glider over repeated sections) and in the Monterey Bay area (use of small fleets, 5 to 10 gliders, operating simultaneously). Other examples of sustained glider observations along repeated tracks are those made in the New Jersey shelf area, on the east coast of the USA (Castelao et al. 2008a) and in the northwestern Mediterranean Sea along a quasi-permanent jet-front system (Bourrin et al. 2009). The high resolution of glider data collected along sustained repeated sections has allowed the seasonal variability of hydrographic fields to be studied (Castelao et al. 2008a), and the coupling between physical and biological process in the upper ocean to be better characterized in time and space (Davis et al. 2008; Perry et al. 2008, Niewiadomska et al. 2008, Hodge and Fratantoni 2009). The benefit of combining glider observations with other types of data (e.g. altimetry and buoys), for example to investigate the dynamics of eddies in the upper ocean (Hátún et

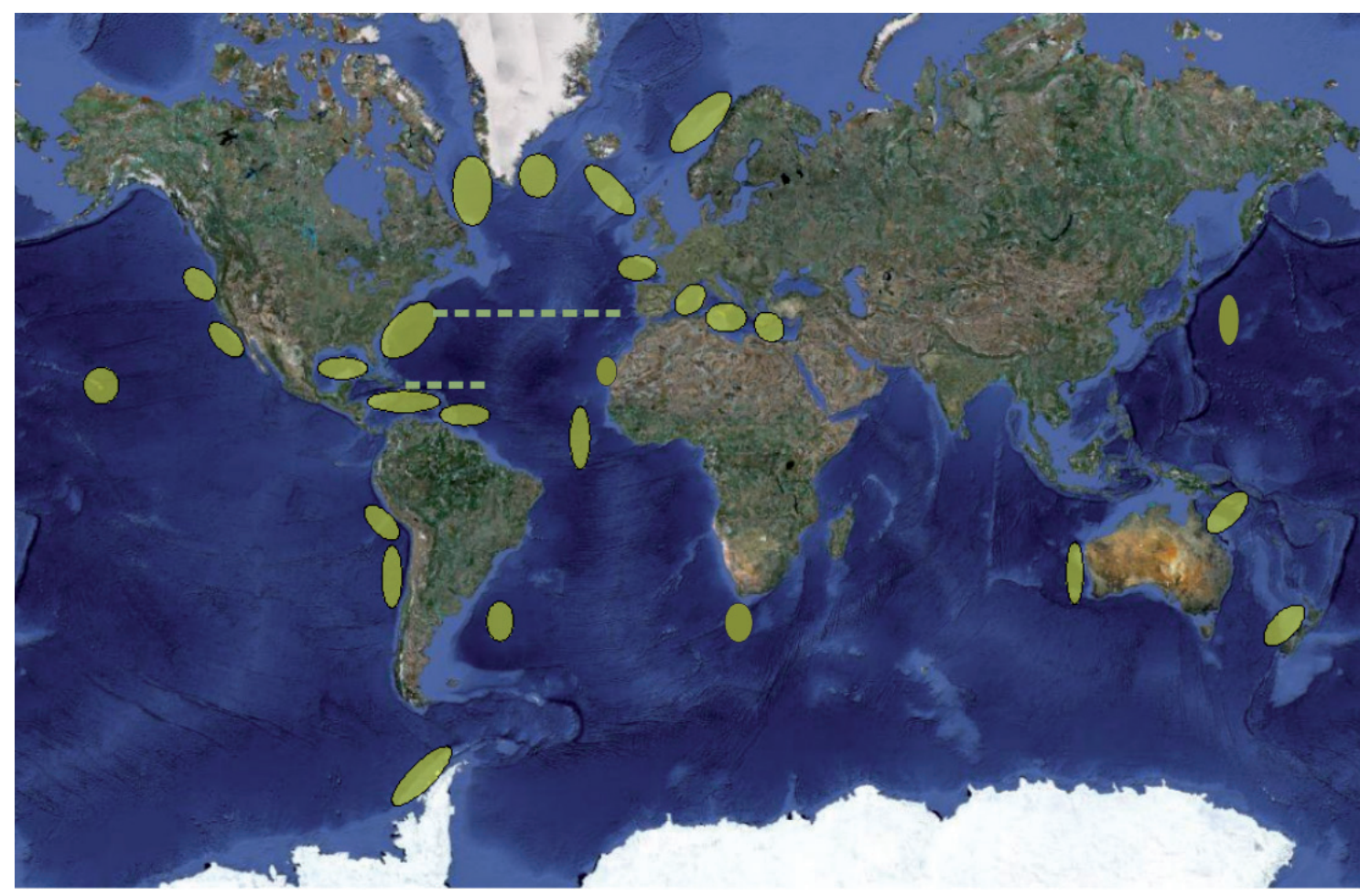

FIG. 1. - World map. Shaded areas indicate regions sampled with gliders in the last 10 years (modified from Testor et al. 2009). A colour version of this figure may be found in the online electronic manuscript. 
al. 2009, Martin et al. 2009) has also been shown. Additionally, gliders have been used to estimate zonal or cross-shelf transport (Gourdeau et al. 2008, Castelao et al. 2008b) and to detect the subsurface effects of global climatic processes, such as El Niño in the California Current (Todd et al. 2011). It is also worth mentioning the improvement in ocean model outputs when glider data assimilation is considered (Shulman et al. 2009, Dobricic et al. 2010).

The TMOOS Department at IMEDEA started to operate Slocum gliders in November 2006 and the first successful mission took place between Mallorca and Ibiza using a shallow glider (Tintoré et al. 2007). This demonstration experiment was done in the framework of the European funded MERSEA project. From 2006 to the present, one of the challenges of the TMOOS Department has been to create a well-coordinated team of technicians, engineers and scientists to maintain an observational programme using these new autonomous vehicles. A detailed description of the scientific and technological objectives related to the use of gliders can be found in the 2010-2013 Strategic Plan of IMEDEA-TMOOS (Tintoré et al. 2009).

This paper summarizes the glider activities carried out in the last 5 years by IMEDEA-TMOOS and is structured as follows. First the glider unit is described in terms of infrastructure, software development, data management and international context. Then, the main scientific results achieved using glider data in combination with other observations are presented. Finally, the summary and perspectives are given.

\section{THE GLIDER UNIT AT IMEDEA-TMOOS}

\section{Infrastructure}

The glider fleet at IMEDEA-TMOOS consists of four Teledyne Webb Research Slocum gliders, one coastal glider (200 $\mathrm{m}$ depth) and three deep gliders $(1000 \mathrm{~m})$. Laboratories and workshops at IMEDEATMOOS provide technical support while additional facilities at Calanova Harbour (Bay of Palma) provide logistic support. The glider facilities include new marine electronics and mechanical laboratories, in operation since 2007, as well as a renovated laboratory for glider ballasting, with a tank, a van and a rubber boat for near-shore coastal operations. A coastal ship and a warehouse/coastal laboratory are available at the Calanova shore station (near the port of Palma de Mallorca) to support glider operations at sea and IMEDEA activities in general.

Additionally, IMEDEA researchers maintain collaboration with the Search and Rescue 801 Squadron (Ministerio de Defensa) based in Palma de Mallorca, a collaboration that started more than 15 years ago with specific missions in the Alborán and Balearic Seas. In the framework of the glider operations, these collaborations have been intensified and extended to now also include the Spanish Maritime Safety and Rescue

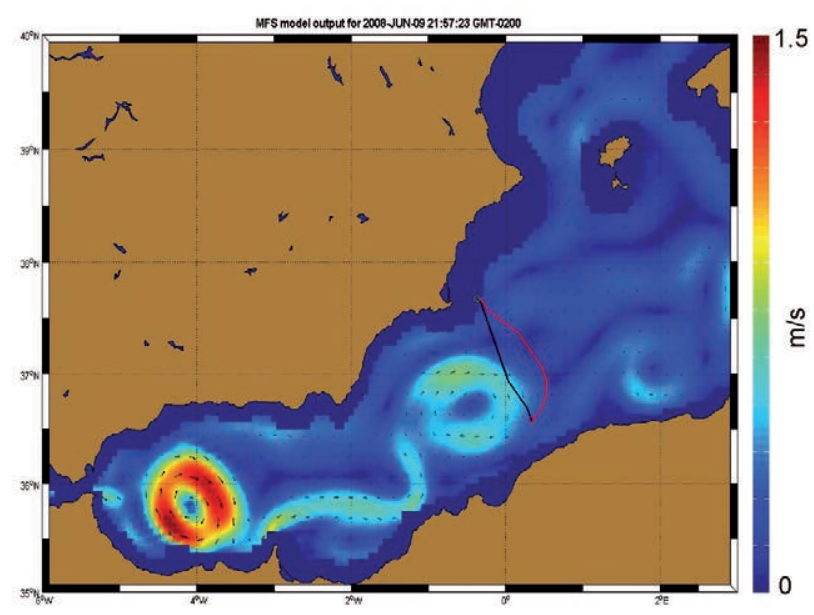

FIG. 2. - MFS model current outputs (magnitude in colour) and estimated glider trajectories from the path planner algorithm (solid black and red lines). A colour version of this figure may be found in the online electronic manuscript.

Agency (SASEMAR, Ministerio de Fomento). A specific example of these joint operations was the successful recovery of a Slocum glider by a Search and Rescue diver operating from a helicopter in 2006.

\section{Navigation and mission definition}

For operations in a complex environment such as the ocean, a priority has been to seek routes for glider missions that can best save and optimize battery energy in order to lengthen the gliders' autonomy. This subject has been extensively investigated at IMEDEA. Álvarez and Caiti (2002) provided simulations of energy saving based on an optimal path planner for AUVs. Later, Álvarez et al. (2004) reviewed the problem using real ocean velocity fields, with successful results. Garau et al. (2005) investigated the optimization of glider tracks based on the minimum-time and considering the presence of mesoscale structures of different sizes. The algorithm developed in this study provides results on the reliability of a glider mission, not only in simulated cases but also in real environmental ocean conditions (Fig. 2). The path planner analysis has been tested with successful results in areas characterized by strong currents $\left(\sim 1 \mathrm{~m} \mathrm{~s}^{-1}\right)$, such as the eastern Alboran Sea (Garau et al. 2009, Ruiz et al. 2009a). Moreover when adaptive sampling strategies that combine gliders with other observations platforms such as Argo profiling floats are employed, the sampling strategy in the studied area is significantly optimized (Alvarez et al. 2007).

\section{The glider data system}

A glider data system was built to enable the processing, analysis and management of all the information provided by the new platforms. Binary files sent by the gliders are converted to ASCII format and then a processing chain is applied. The final steps include the 


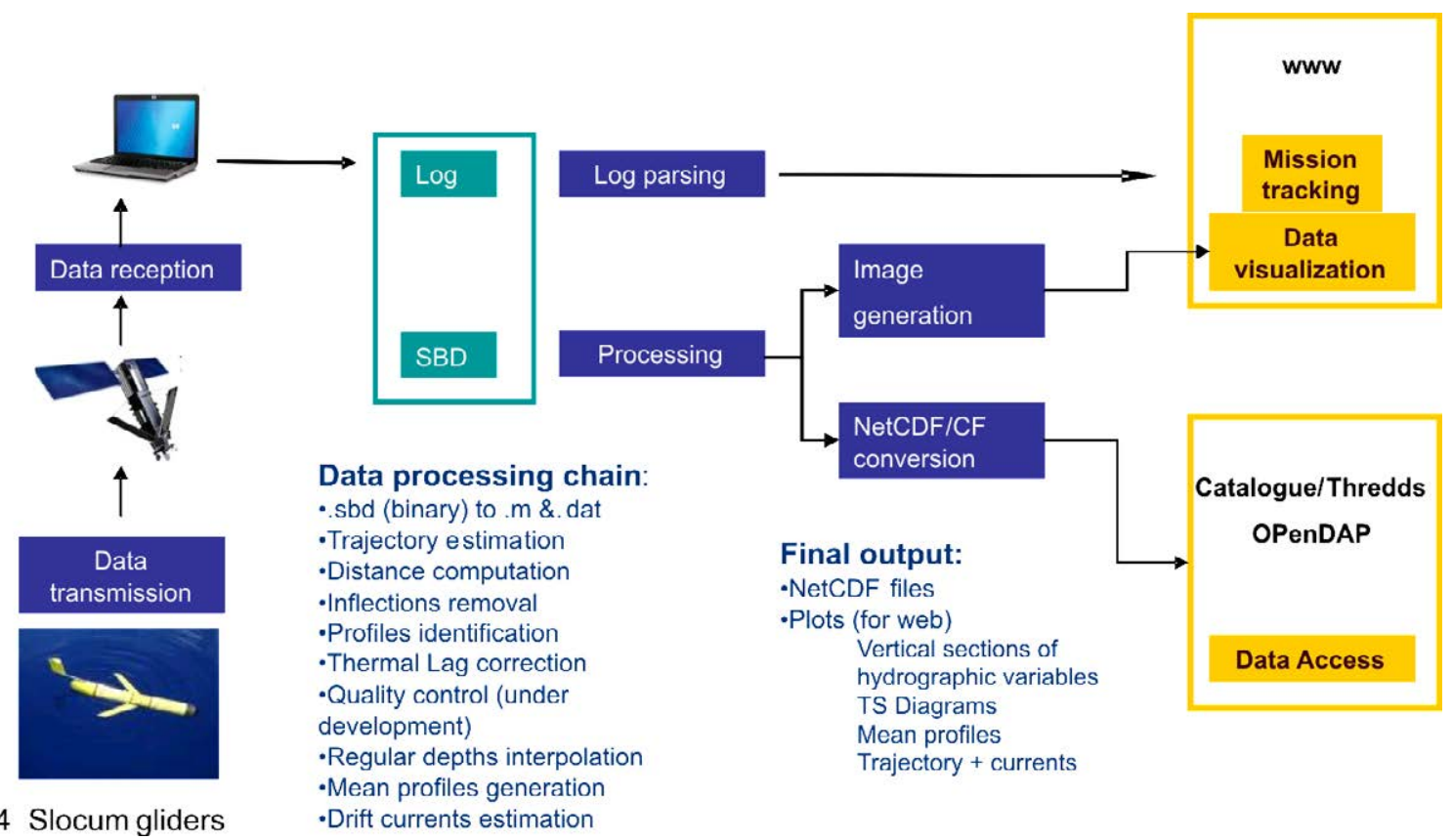

FIG. 3. - Diagram of the IMEDEA Glider Data System. A colour version of this figure may be found in the online electronic manuscript.

generation of images and standard NetCDF (Network Common Data Form) format files for data visualization and dissemination. Below, the main parts of the glider data system (Fig. 3) are described.

\section{Real-time tracking and visualization}

A web tool was developed for glider mission definition and real-time tracking (http://www.imedea. uib-csic.es/tmoos/gliders/). As described above, when a glider surfaces, it connects to the land station via satellite Iridium communication and transmits binary files. Normally, about 30 minutes are needed for this data transmission, which includes information on positioning (latitude, longitude), scientific records (such as temperature, conductivity, pressure, dissolved oxygen, fluorescence and turbidity) and other performance indicators such as battery energy, interior humidity and vacuum. After the preliminary level of data processing, described below, oceanographic and engineering variables are displayed on the website for mission evaluation. Using this real-time information and considering the environmental conditions, such as currents in the study area and bathymetry, as well as other constraints such as vessel traffic and battery energy, decisions are taken to resume the mission or pilot the glider (change the mission waypoints), using optimal routes obtained from the path planner algorithm.

\section{Data processing: real-time and delayed mode}

Two levels of processing were established: realtime and delayed mode. The first includes binary to ASCII conversion, data sub-sampling, inflection removal, profile identification and averaging. Variables such as salinity, density and drift current estimation are also computed for real-time visualization. In delayed mode, a more detailed and specific processing chain is applied, including thermal lag correction, filtering, $1 \mathrm{~m}$ bin vertical averaging and computation of derived variables (e.g. geostrophic velocity and mixed layer depth). It is worth mentioning the new methodology developed at IMEDEA for the thermal lag correction of conductivity data from the unpumped CTD sensors installed on Slocum gliders (Garau et al. 2011). The main advance on previous work for standard ship CTDs is that the new scheme takes into account the variable speed of the glider. Salinity errors of up to 0.3 induced by thermal lag were found and successfully corrected (Fig. 4). Additionally, following the methodology described by Merckelbach et al. (2010), a compass calibration experiment was incorporated into the routine maintenance of the IMEDEA glider fleet. This procedure estimates the compass angle error on board the platform and enables the correction of induced spurious velocities when integrated glider currents are computed.

\section{Data management}

Data management is defined as "the development and execution of architectures, policies, practices and procedures that properly manage the full data lifecycle needs of an enterprise" (The Data Management Association International, DAMA). In the framework of oceanography, data management includes all the processes from data acquisition to dissemination, including specific quality control and archival procedures. Gliders provide a huge amount of scientific and engineering data that needs to be properly managed and combined 

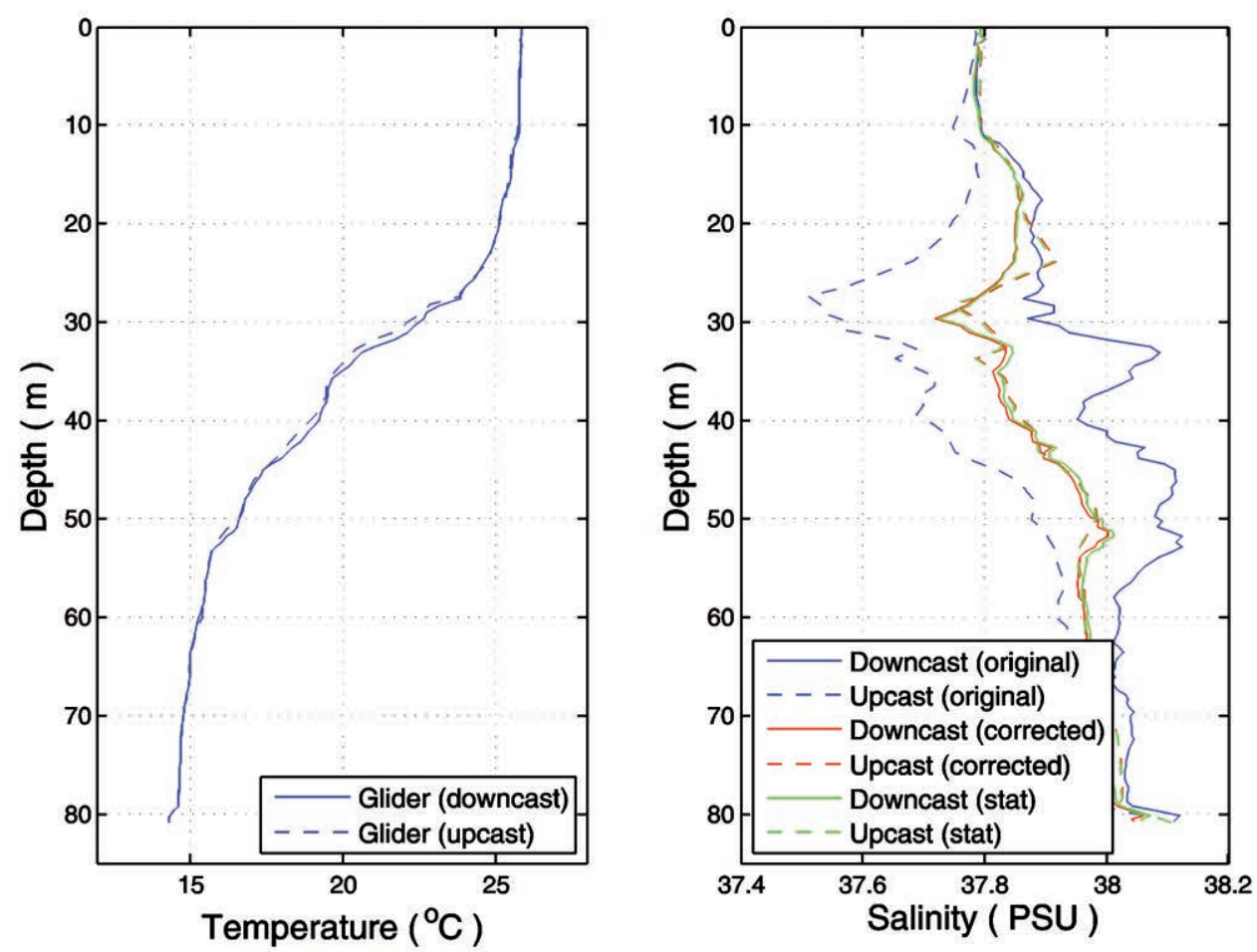

FIG. 4. - Temperature and salinity profiles (downcast and upcast) from glider. Blue (dark) line corresponds to original profiles, red (medium) to corrected profiles using the new methodology proposed by Garau et al. (2011) and green (light) to profiles corrected with statistical median parameters. A colour version of this figure may be found in the online electronic manuscript.

with metadata (e.g. mission name, deployment day, waypoints, glider configuration and mission objectives) to allow users to locate, share, download, visualize, analyze and use the information. An internal web tool was developed to record metadata information associated with each glider mission and a relational database is then used to query glider deployment information on the glider website. Data archiving is done in NetCDF format, as this is increasingly becoming a standard format for the sharing of oceanographic data (e.g. the Argo database). Metadata from the relational database are also integrated into the NetCDF file. For data discovery, a Thematic Real-time Environmental Distributed Data Services (THREDDS) project was set-up to simplify the discovery and use of scientific data. Finally, the data management process enables access to the data via protocols such as the HyperText Transfer Protocol (HTTP), the File Transfer Protocol (FTP) and the Open-source Project for a Network Data Access Protocol (OPENDAP).

\section{IMEDEA glider unit within the international context}

The glider unit at IMEDEA has evolved significantly and developed during the last four years, establishing strong collaborations with international groups operating gliders to exchange experiences and expertise on these new platforms. In Europe, there are permanent links between the glider unit at IMEDEA and the emerging European coastal observatories such as the Mediterranean Ocean Observing System on Environment (MOOSE) in France and the NATO Undersea Research Centre (NURC) glider facility in Italy. In the USA contacts are maintained with Rutgers University and the University of Washington, both of which have vast experience in glider operations. The Integrated Marine Observing System (IMOS) in Australia has incorporated gliders into the observing system with a strategic view of long-term monitoring with this new platform, a view shared by IMEDEA.

\section{GLIDERS FOR OCEAN RESEARCH}

\section{Observational programme along altimetry satellite tracks}

The IMEDEA glider team has been leading an intensive observational programme in the Balearic Sea (Western Mediterranean) using gliders and altimetry data from ENVISAT, and Jason-1 and Jason-2 satellites. The aim of the study was i) to test the feasibility of the new technologies to study coastal areas with intense mesoscale activity; ii) to investigate the use and potential improvements to the altimetry data obtained from ENVISAT and Jason satellites in the coastal area (in terms of waveform re-tracking, corrections and coastal-oriented editing strategies); and iii) to characterize the mesoscale variability of the Balearic Sea using high-resolution glider data. 

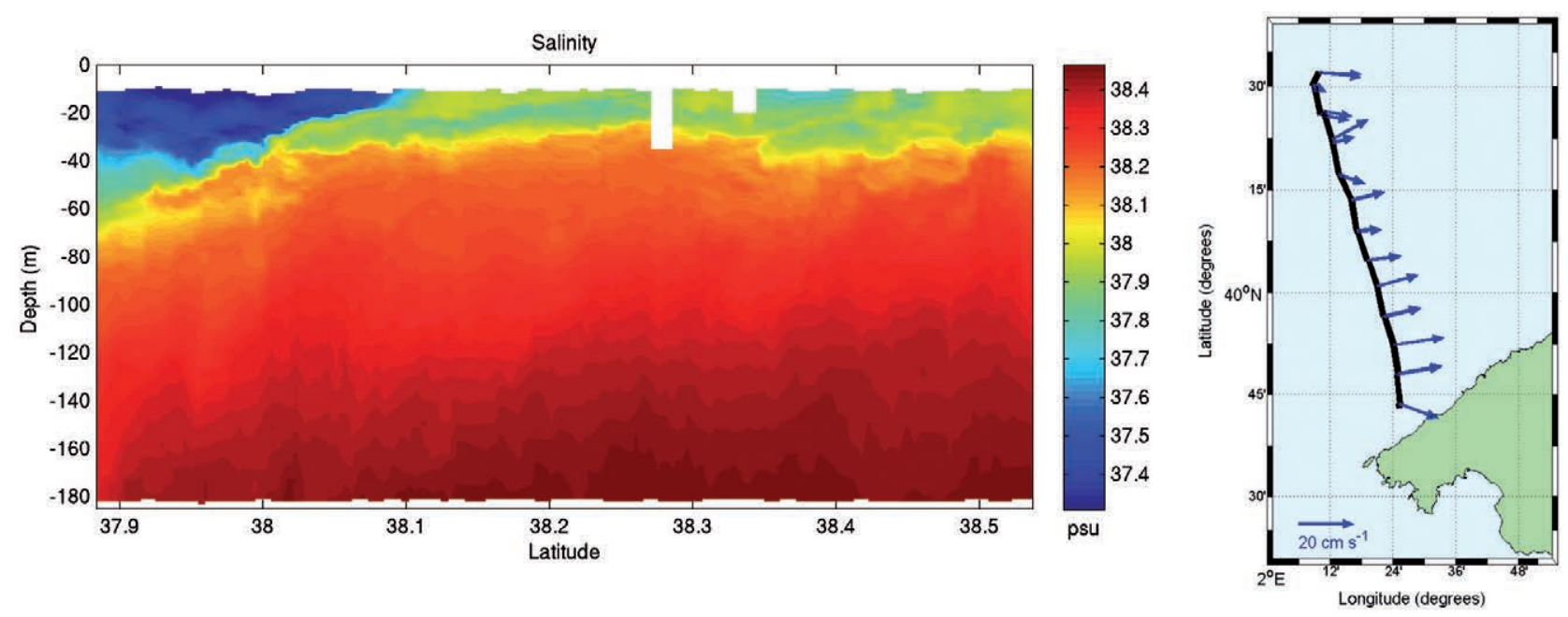

FIG. 5. - Vertical section of salinity field obtained from the glider data during a mission carried out in July 2007 (left). Glider trajectory and integrated horizontal velocities $(0-180 \mathrm{~m})$ obtained from glider GPS positioning (right). A colour version of this figure may be found in the online electronic manuscript.

The sampling strategy consisted of repeated glider legs along sections that are coincident with ENVISAT or Jason 1 and 2 tracks and approximately perpendicular to the Balearic and Northern Currents. From 2007 to 2010, nine missions were performed, always simultaneously with the passage of ENVISAT or Jason-1/-2 satellites. Glider hydrographic data from this observational programme has confirmed the high mesoscale variability of the ocean circulation in the Balearic Sea, including the presence of anomalous anticyclonic eddies in the middle of the sub-basin and near the northern coast of Mallorca. The relatively low salinity values (about 37.4) sampled by the glider along this coast (Fig. 5) reveal that the Balearic Current (mean width of about $40 \mathrm{~km}$ and depth of about $200 \mathrm{~m}$ ) is clearly enhanced by Atlantic Water flowing through the Mallorca Channel (Ruiz et al. 2009b). Also, a maximum integrated velocity of 20 $\mathrm{cm} \mathrm{s}^{-1}$ for flows between 0 and $180 \mathrm{~m}$ was found associated with the Balearic Current (Fig. 5). These velocities can be obtained from GPS glider positioning, taking into account the theoretical waypoints defined in the mission and the deviation of glider trajectory due to horizontal currents. In addition, absolute dynamic topography from altimetry data reveals good coherence with the dynamic height, as calculated from glider data, where there are common observations (see Ruiz et al. 2009b, Bouffard et al. 2010 for details).

An example of the high mesoscale variability detected in the Balearic Sea is found in the April 2008 glider mission, in which an anomalous anticyclonic eddy was sampled by one of the glider platforms when it performed a mission between Mallorca and the Iberian Peninsula. The presence of this kind of anomalous eddy, which reverses the typical circulation of the area, was previously reported by Pascual et al. (2002), but a high-resolution picture of the internal structure was now possible (Fig. 6) using data from a coastal glider (see Bouffard et al. 2010).
The glider observational programme conducted along altimeter tracks has also improved the altimetricderived velocity computations in coastal areas, using higher-frequency altimeter data sampling combined with a novel coastal-oriented editing strategy developed at IMEDEA-TMOOS (Bouffard et al. 2010).

\section{Mesoscale and sub-mesoscale processes: physical and biogeochemical coupling}

The high-resolution physical and biogeochemical data collected by these new platforms is of utmost importance to increasing our understanding of processes in the upper ocean, such as the adjustment between Atlantic and Mediterranean waters and the consequences for biological processes. This was the purpose of a glider mission carried out by the IMEDEA glider team in the eastern Alboran Sea (western Mediterranean), from July 4 to 18,2008 (SESAME IP project). The glider mission was designed to cross the Almeria-Oran front, from approximately 30 miles east of the Spanish coast off Cartagena to a waypoint 20 miles off the Algerian coast. This area is characterized by intense currents of the order of $1.5 \mathrm{~m} \mathrm{~s}^{-1}$ and significant mesoscale activity, and the deployment of a glider in such an energetic area was both a scientific and technological challenge. The path-planning algorithm (Garau et al. 2005), as mentioned above, was used to test the feasibility of the glider mission and three different types of velocity fields available for the study area were considered as input for evaluating the success/failure of the mission. These were the Mediterranean Forecasting System model outputs (Tonani et al. 2008), derived velocities from mean dynamic topography (Rio et al. 2007) and Altimetry Sea Level Anomalies (http://www.aviso.oceanobs.com). The results from the algorithm suggested that glider navigation in the study area was theoretically possible (Fig. 2), so the 

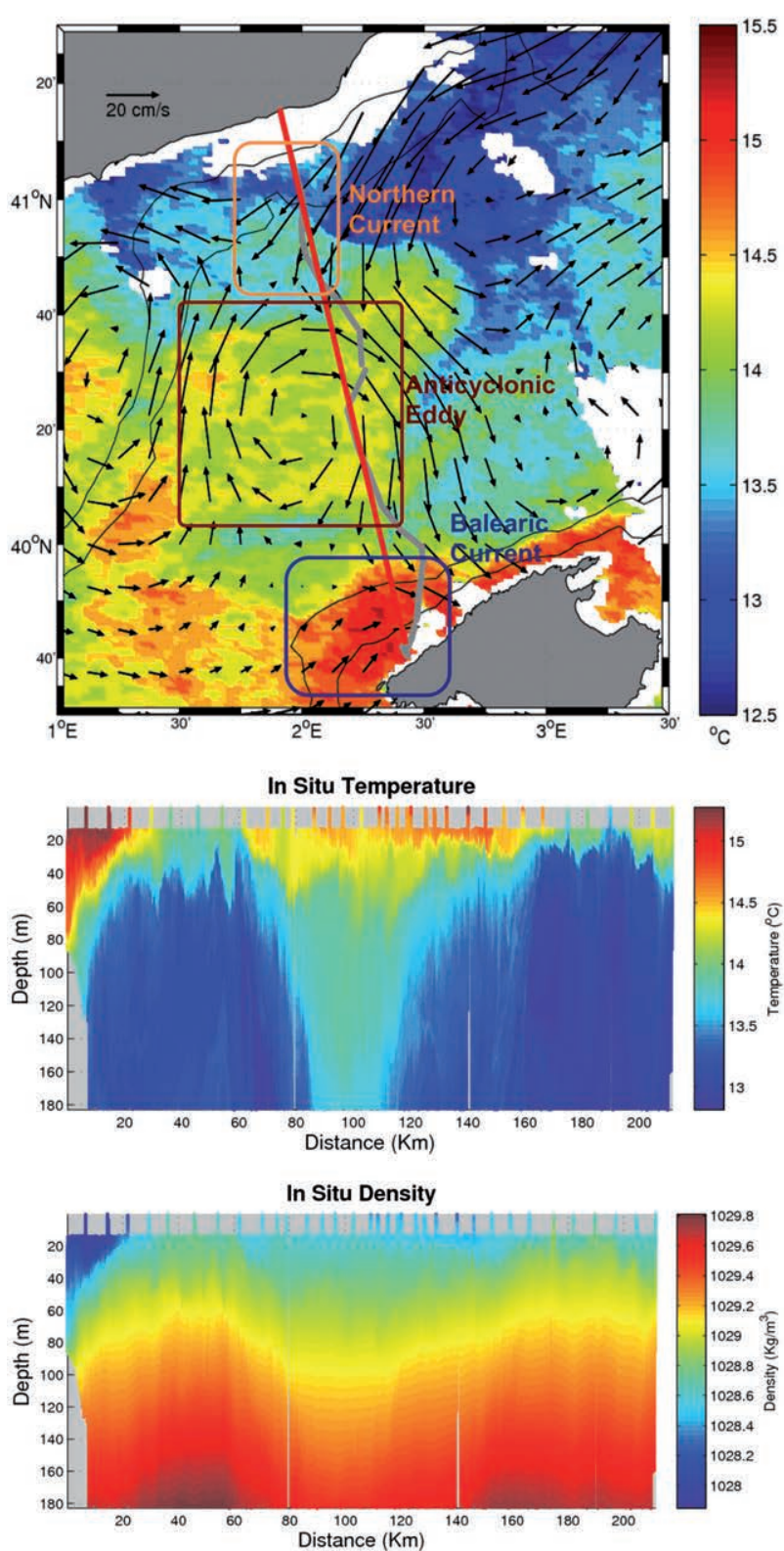

FIG. 6. - (a) Night AVHRR Sea Surface Temperature image for 16 April 2008 (background colour). Vectors correspond to geostrophic velocity derived from altimetry. The squares indicate the main oceanographic structures observed. Red (drack) line corresponds to altimetry track and grey line to glider trajectory during the April 2008 mission. (b) Along-track vertical section of temperature and (c) density obtained from glider mission. A colour version of this figure may be found in the online electronic manuscript.

glider was deployed. It recorded a total of 1311 profiles (CTD, fluorescence and turbidity) between the surface and $180 \mathrm{~m}$ depth at $\sim 0.5 \mathrm{~km}$ horizontal resolution. The frontal zone, between the two main water masses (Atlantic and Mediterranean), was clearly sampled by the glider, showing that relatively fresh and cold Atlantic Water was driving a higher concentration of chlorophyll (Fig. 7). Moreover, during the glider sampling period, altimetry data revealed the formation and evolution of a $\sim 100 \mathrm{~km}$ diameter eddy in the area, with a clear eastward displacement (not shown). This large structure had associated vertical velocities (diagnosed using the Omega equation) of $\sim 1 \mathrm{~m} \mathrm{day}^{-1}$ (Ruiz et al. $2009 \mathrm{c}$ ), which is in agreement with previous studies in the area for similar-sized eddies (Tintoré et al. 1991). For smaller-sized structures visible in the analysis (eddy diameter $<100 \mathrm{~km}$ ), vertical velocities can reach values of about 40 to $50 \mathrm{~m} \mathrm{day}^{-1}$ (Gomis et al. 2001, Allen et al. 2001).

\section{Multi-platform experiments: SINOCOP}

The SINOCOP project is an example of how data from gliders can be integrated with other datasets in a multi-platform experiment to study mesoscale and submesoscale processes in coastal areas. The general goal of the experiment was to develop new methodologies to estimate the three-dimensional state of the ocean using a multi-sensor approach (Pascual et al. 2010).
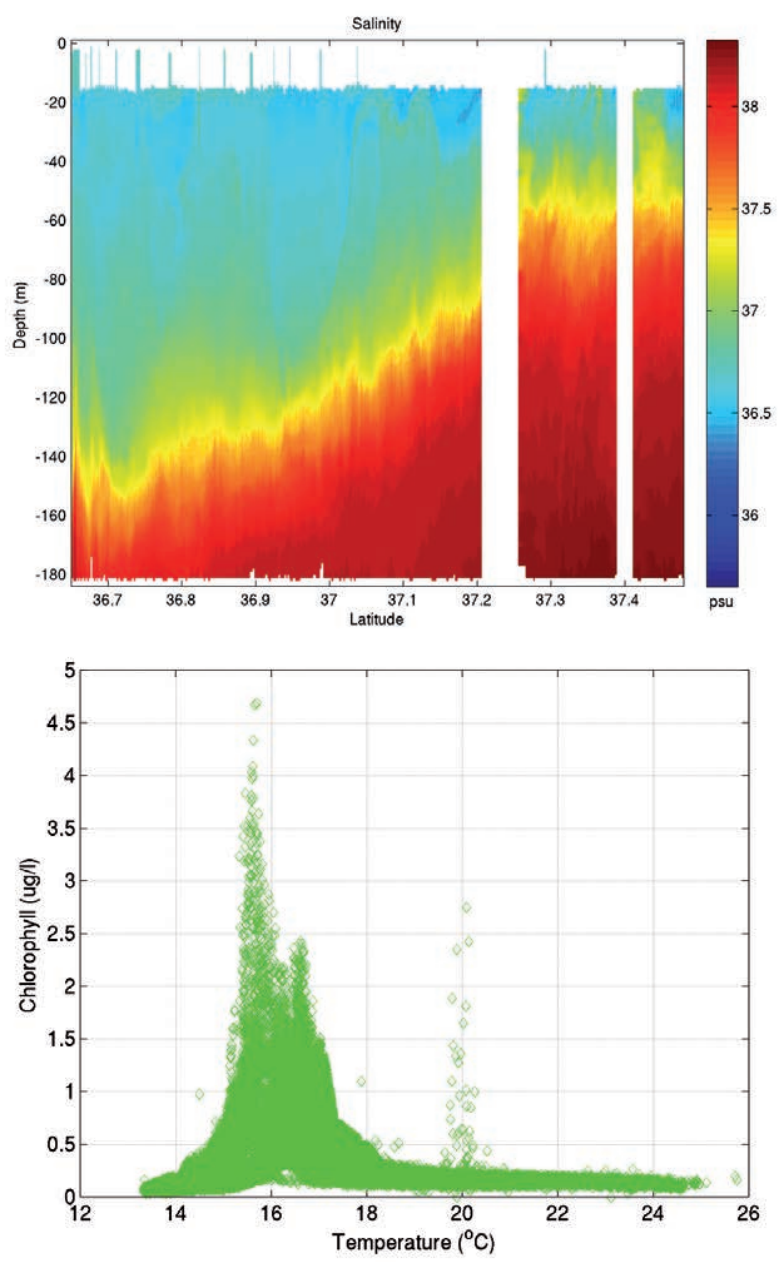

FIG. 7. - Vertical section of raw salinity data (top) obtained during a glider mission in the eastern Alboran Sea, July 2008 (white bands correspond to periods during which CTD sensors did not collect data due to internal electronic problems). Chlorophyll $\left(\mu \mathrm{g} \mathrm{l}^{-1}\right)$ vs. temperature $\left({ }^{\circ} \mathrm{C}\right)$ (bottom) for the same mission (bottom). A colour version of this figure may be found in the online electronic manuscript. 

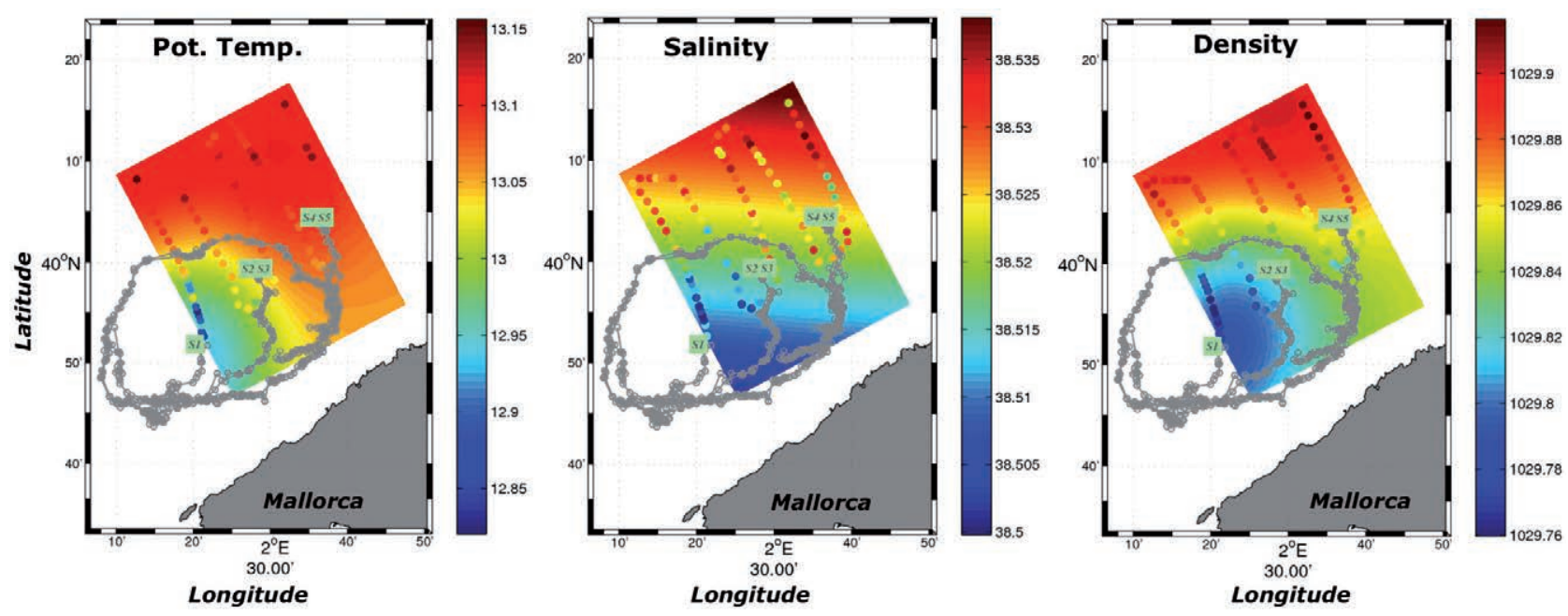

FIG. 8. - Optimal interpolation fields of temperature $\left({ }^{\circ} \mathrm{C}\right)$, salinity (PSU) and density $\left(\mathrm{kg} \mathrm{m}^{-3}\right)$ at $75 \mathrm{~m}$. Coloured dots correspond to values measured by gliders' CTD payload. Grey solid lines and dots are the drifter's trajectories. A colour version of this figure may be found in the online electronic manuscript.

The fieldwork was carried out along the north coast of Mallorca (Western Mediterranean), from 11 to 21 May 2009. Equipment for the sampling included one coastal and one deep glider, Surface Velocity Program (SVP) drifters, MD02 low-cost Lagrangian coastal drifters, standard ship-based CTDs and remote sensing observations (altimetry, sea surface temperature and ocean colour). The two gliders covered a regular grid of $50 \times 40$ $\mathrm{km}^{2}$ with a resolution of $4 \mathrm{~km}$ between transects, which in combination with the drifters and ship CTD profiles allowed dynamical structures of the size of the first internal Rossby radius ( $20 \mathrm{~km}$, Tintoré et al. 1991) to be well sampled. Preliminary results show the presence of a 45-km-diameter anticyclonic eddy near the northern coast of Mallorca that modified the flow of the Balearic Current. The eddy has a coherent vertical structure in the upper ocean, as is shown by the optimal interpolation fields of temperature, salinity and density at $75 \mathrm{~m}$. At sub-surface, the glider data allows high-resolution characterization of the vertical structure of the eddy cold-core, while at the surface drifters released during the experiment tracked its horizontal displacement (Fig. 8). Comparisons with altimetry data reveal that altimeter gridded products do not have sufficient resolution for the detection of the small mesoscale $(\sim 20-100 \mathrm{~km})$ and sub-mesoscale $(<20 \mathrm{~km})$ features present in the glider fields and in the drifter data (Fig. 8). This highlights the need for synergetic approaches combining observing systems at several spatial/temporal scales with the aim of gaining a better understanding of sub-mesoscale signals. An in-depth analysis of the SINOCOP dataset is currently being conducted to study the dynamics of the structures captured by the gliders.

\section{Routine monitoring in the Balearic Channels}

It is known that the inflow of Atlantic Water through the Balearic Channels is related to important local eco- system changes, such as the Bluefin Tuna spawning area south of the Balearic Islands. Using data gathered (seasonally) in the late 1990s, Pinot et al. (2002) characterized the variability of this circulation in the channels. Since January 2011, a new sustained monthly observational programme in the Balearic Channels is being conducted by IMEDEA and SOCIB, the new Balearic Islands Coastal Observing and Forecasting System. This monitoring program consists of repeated transects between Mallorca, Ibiza and Denia (Fig. 9). In 2011, seven glider missions were successfully carried out in the Ibiza Channel, reporting an unprecedented spatial and temporal variability in transports (Heslop et al. 2011). The combination of these glider data with information from other platforms (satellites, ship cruis-

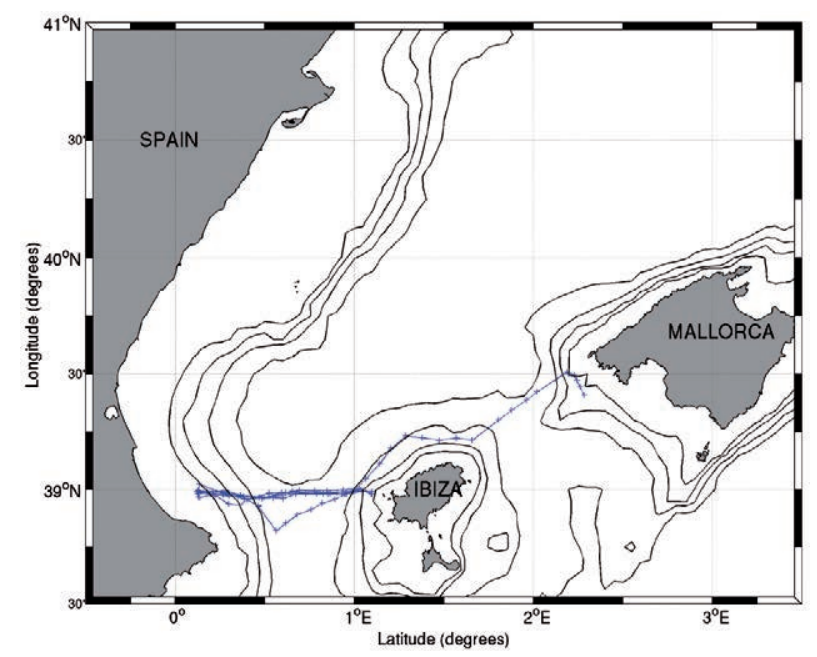

FIG. 9. - Glider track (blue line) during the January 2011 mission in the Balearic Channels. The glider sampling is maintained roughly on a monthly basis. Isobaths of 100, 200, 500 and 1000 are plotted (black solid lines). A colour version of this figure may be found in the online electronic manuscript. 
es, high-frequency radars and buoys) will support the investigation of unresolved scientific questions such as mesoscale, seasonal and inter-annual variability of the water exchanges in the Ibiza and Mallorca Channels.

\section{CONCLUSION}

In the last five years, the IMEDEA glider team has been one of the most proactive groups in Europe, operating Slocum gliders in the western Mediterranean. To date 22 glider missions have been carried out, collecting about 17000 hydrographic and biogeochemical profiles. Electronic and maintenance laboratories have been set up in order to establish a key glider port in this region of the Mediterranean Sea and to offer facilities to other groups operating gliders. Many groups have already benefited from the use of the IMEDEA facilities for testing and operating their gliders, including teams from France and the United Kingdom.

In terms of glider data calibration and processing, a great effort has been made, and is still ongoing, to adapt and improve existing processing tools from conventional oceanographic platforms and apply them to these new AUVs. Gliders gather a huge amount of scientific and mechanical/engineering information that needs to be properly managed. Following experience acquired in other international programmes, such as Argo, the standard NetCDF format has been adopted for the IMEDEA glider data and tools have been developed to archive, search and distribute the data to end-users.

Using the high-resolution data collected by autonomous underwater platforms such as gliders, one of the challenges at IMEDEA-TMOOS is to better understand and quantify the importance of sub-mesoscale processes $(1-20 \mathrm{~km})$ in the upper ocean, including the coupling between physical and biogeochemical processes in the marine ecosystem (Ruiz et al. 2009c). In addition, glider data are leading to the development of new methodologies to improve coastal altimetry, as demonstrated in Bouffard et al. (2010).

It is also essential to highlight the contribution of this new platform to routine monitoring in the Balearic Sea, by obtaining high-quality 3D observations in an area where oceanic climatologies are of limited use given the few available historical observations. This lack of historical climatologies affects our basic understanding of the oceanography of the southern Balearic Sea.

In addition to these scientific objectives, gliders are important platforms for the development of new operational oceanography tools and applications. They are useful vehicles on which to develop and implement new sensors for ocean monitoring and for increasing the safety of glider operations and navigation (Alvarez et al. 2001, Garau et al. 2005). Gliders can also help to monitor water quality in coastal waters and provide specific data to support the science-based implementation of the EU Water Directive.
The IMEDEA glider team is one of the core members of the international glider initiative EGO (Everyone's Gliding Observatories, http://www.egonetwork.org). Initially this was aimed at coordinating the few European groups starting glider activities in the framework of EU-funded MFSTEP and MERSEA projects, but since 2009 EGO has expanded to become a global international network for research groups operating gliders (Testor et al. 2009). At an international workshop and glider school held every year, glider teams, manufacturers and oceanography companies from around the world share technical and scientific experiences.

Gliders are today becoming a key component of the new ocean-observing systems being developed around the world, such as IMOS in Australia, OOI (Ocean Observatories Initiative) in the USA and MOOSE in France (Testor et al. 2009). In line with all these initiatives, the new Balearic Island Coastal Observing and Forecasting System (SOCIB) will address international scientific and technological coastal ocean priorities. This coastal observatory, in place since 2010, has included in its implementation plan the use of gliders, in coordination with other ocean observing platforms such as buoys, high frequency radars and geophysical satellites. From 2011 onwards, the new SOCIB glider facility, in coordination with the IMEDEA glider unit, will operate a fleet of gliders that will help to characterize the physical and biogeochemical processes and properties of the marine ecosystem.

\section{ACKNOWLEDGEMENTS}

We would like to thank the Search and Rescue team from Escuadrón 801 (Ministerio de Defensa), SASEMAR (Ministerio de Fomento), Underwater Operations of the Spanish Army and the Port of Soller for their collaboration in the glider operations. Special thanks are due to Cayetana Casas and Matías Bonet for their efficient collaboration during glider missions. The glider activities were carried out in the framework of the following projects funded at European (European Commission), national (Ministerio de Ciencia e Innovación) and local (Govern de Les Illes Balears) level: MERSEA, SESAME, ECOOP, PNC-Medio Ambiente, SINOCOP, AC-OUTFLOW and GLIDERBAL. The altimeter data were produced by SSALTO/ DUACS and distributed by AVISO with support from CNES.

\section{REFERENCES}

Allen J.T., Smeed D. A., Tintoré J., Ruiz S. 2001. Mesoscale subduction at the Almeria-Oran front. Part 1: Ageosotrophic flow, J. Marine Syst., 30: 263-285.

Alvarez A., Caiti A. 2001. A genetic algorithm for autonomous underwater vehicle route planning in ocean environments with complex space-time variability. In: Proceedings of the IFAC Control Applications of Marine Systems (CAMS 2001).

Alvarez A., Caiti A. 2002. Interactions of autonomous underwater vehicles with variable scale ocean structures. In: Proceedings of 
the IFAC World Conference Systems.

Alvarez A., Caiti, Onken R. 2004. Evolutionary path planning for autonomous underwater vehicles in a variable ocean. IEEE J. Oceanic Eng., 29: 418-429.

Alvarez A., Garau B., Caiti A. 2007. Combining networks of drifting profiling floats and gliders for adaptive sampling of the Ocean, IEEE International Conference on Robotics and Automation, Roma, Italy, 10-14.

Bouffard J., Pascual A., Ruiz S., Faugere Y., Tintoré J. 2010. Coastal and mesoscale dynamics characterization using altimetry and gliders: A case study in the Balearic Sea, J. Geophys. Res., 115: C10029.

Bourrin F, Taillandier V., Prieur L., Claustre H., Poteau A., d'Ortenzio F. 2009. Seasonal variability of physical and biogeochemical coupling at submesoscale across the Ligurian Current, NW Mediterranean, $4^{\text {th }}$ EGO meeting, 16-20 November, Cyprus.

Castelao R., Glenn S., Schofield O., Chant R., Wilkin J., Kohut J. 2008a. Seasonal evolution of hydrographic fields in the central Middle Atlantic Bight from glider observations. Geophys. Res. Lett. 35: L03617.

Castelao R., Schofield O., Glenn S., Chant R., Kohut J. 2008 b. Cross-shelf transport of freshwater on the New Jersey shelf, $J$. Geophys. Res., 113: C07017.

Davis R., Ohman M.D., Rudnick D.L., Sherman J., Hodges B. 2008 : Glider surveillance of physics and biology in the southern California Current System, Limnol. Oceanogr. 53: 2151-12168.

Dobricic S., Pinardi N., Testor P., Send U. 2009. Impact of data assimilation of glider observations in the Ionian Sea (Eastern Mediterranean). Dyn. Atmos. Oceans. 50: 78-92.

Eriksen C., Osse T. J., Light R. D., Wen T., Lehman T.W., Sabin P.L., Ballard J.W., Chiodi A.M. 2001. Seaglider: A long-range autonomous underwater vehicle for oceanographic research. IEEE J. Oceanic Eng. 26: 424-436

Eriksen, C. 2010. The autonomous revolution. Transforming ocean observation with mobile platfoms, (Sverdrup Lecture), AGU Fall Meeting, 13-17, San Francisco.

Garau B., Alvarez A., Oliver G. 2005. Path planning of autonomous underwater vehicles in current fields with complex spatial variability: an A* approach. In Proceedings of the 2005 IEEE International Conference on Robotics and Automation, 195-199.

Garau B., Bonet M., Alvarez A., Ruiz S., Pascual A. 2009. Path Planning for Autonomous Underwater Vehicles in Realistic Oceanic Current Fields: Application to Gliders in the Western Mediterranean Sea, J. Marit. Res. VI: 5-22.

Garau B., Ruiz S., Zang G.W., Heslop E., Kerfoot J., Pascual A., Tintoré J. 2011. Thermal lag correction on Slocum CTD glider data, J. Atmos. Ocean. Tech. 28: 1065-1074

Gomis D., Ruiz S., Pedder M. A. 2001. Diagnostic analysis of the 3D ageostrophic circulation from a multivariate spatial interpolation of CTD and ADCP data, Deep-Sea Res. I, 48: 269-295.

Gourdeau L., Kessler W.S., Davis R.E., Sherman J., Maes C., Kestenare E. 2008. Zonal Jets Entering the Coral Sea, J. Phys. Oceanogr. 38: 715-725.

Hátún H., Eriksen C.C., Rhines P.B. 2007. Buoyant Eddies Entering the Labrador Sea Observed with Gliders and Altimetry. J. Phys. Oceanogr. 37: 2838-2854.

Heslop E., Ruiz S., Garau B., Allen J., Tintoré J., Lopez-Jurado J.L., Schroeder K. 2011. Variability in upper layer transports in the Balearic Sea, using new data from glider missions. $5^{\text {th }}$ Everyone's Gliding Observatories Workshop, 14-18 March, Gran Canaria, Spain.

Hodges B.A., Fratantoni D.M. 2009. A thin layer of phytoplankton observed in the Philippine Sea with a synthetic moored array of autonomous gliders, J. Geophys. Res., 114: C10020.

Martin J.P., Lee C.M., Eriksen C., Ladd C., Kachel N.B. 2009. Glider observations of kinematics in a Gulf of Alaska eddy, $J$. Geophys. Res. 114: C12021.

Merckelbach L., Smeed D., Griffiths G. 2010. Vertical Water Velocities from Underwater Gliders. J. Atmos. Ocean. Tech. 27: 547-563.

Niewiadomska K., Claustre H., Prieur L., D’Ortenzio F. 2008. Submesoscale physical-biogeochemical coupling across the Ligurian current (northwestern Mediterranean) using a bio-optical glider, Limnol. Oceanogr. 53: 2210-2225.

Pascual A., Buongiorno Nardelli B., Larnicol G., Emelianov M., Gomis D. 2002. A case of an intense anticyclonic eddy in the
Balearic Sea (western Mediterranean), J. Geophys. Res. 107: 3183.

Pascual A., Ruiz S., Tintoré J. 2010. A multi-platform experiment for understanding coastal processes, Sea Technol. July issue: $32-36$

Pinot J.M., López-Jurado J.L., Riera M., 2002. The CANALES experiment (1996-98). Interannual, seasonal, and mesoscale variability of the circulation in the Balearic Channels. Prog. Oceanogr. 55: 335-370.

Perry, M.J., Sackmann B.S., Eriksen C.C., Lee C.M. 2008. Seaglider observations of blooms and subsurface chlorophyll maxima off the Washington coast. Limnol. Oceanogr. 53: 2169-2179.

Rio M.-H., Poulain P.M., Pascual A., Mauri E., Larnicol G., Santoleri R. 2007. A mean dynamic topography of the Mediterranean Sea computed from altimetric data, in-situ measurements and a general circulation model. J. Mar. Syst. 65: 484-508.

Rudnick D., Davis R., Eriksen C., Fratantoni D., Perry M. J. 2004 Underwater Glider for Ocean Research, Mar. Technol. Soc. J. 38: $48-59$

Ruiz S., Garau B., Martínez-Ledesma M. 2009a. Monitoring the Eastern Alboran sea using high resolution glider data, Sea Technol. March issue: 29-32.

Ruiz S., Pascual A., Garau B., Faugere Y., Alvarez A., Tintoré J. 2009b. Mesoscale dynamics of the Balearic front integrating glider, ship and satellite data. J. Mar. Syst. 78: S3-S16.

Ruiz S., Pascual A., Garau B., Pujol I., Tintoré J. 2009c. Vertical motion in the upper ocean from glider and altimetry data. Geophys. Res. Lett. 36: L14607, doi:10.1029/2009GL03856.

Sherman J., Davis R. E., Owens W. B., Valdes J. 2001. The autonomous underwater glider "Spray". IEEE J. Oceanic Eng. 26: 437-446.

Shulman I., Rowley C., Anderson S., DeRada S., Kindle J., Martin P., Doyle J., Cummings J., Ramp S., Chavez F., Fratantoni D., Davis R. 2009. Impact of glider data assimilation on the Monterey Bay model. Deep-Sea Res. II 56: 188-198.

Siegel E. 2009. Capabilities for gliders, Marine Technology Reporter, October Issue, 28-34

Stommel H. 1989. The SLOCUM mission. Oceanography April: 22-24.

Testor P., Meyers G., Pattiaratchi C., Bachmayer R., Hayes D., Pouliquen S., Petit de la Villeon L., Carval T., Ganachaud A., Gourdeau L., Mortier L., Claustre H., Taillandier V., Lherminier P., Terre T., Visbeck M., Krahman G., Karstensen J., Alvarez A., Rixen M., Poulain P.M., Osterhus S., Tintoré J., Ruiz S., Garau B., Smeed D., Griffiths G., Merckelbach L., Sherwin T., Schmid C., Barth J.A., Schofield O., Glenn S., Kohut J., Perry M.J., Eriksen C., Send U., Davis R., Rudnick D., Sherman J., Jones C., Webb D., Lee C., Owens B., Fratantoni D. 2009. Gliders as a component of future observing systems, In Proceedings of OceanObs'09: Sustained Ocean Observations and Information for Society (Annex), Venice, Italy, 21-25 September 2009, Hall, J., Harrison, D.E. \& Stammer, D., Eds., ESA Publication WPP-306.

Tintoré J., Gomis D., Alonso S., Parrilla G. 1991. Mesoscale dynamics and vertical motion in the Alboran Sea, J. Phys. Oceanogr. 21: 811-823.

Tintoré J., Alvarez A., Casas B., Garau B., Vizoso G., Testor P., Send U., Lherminier P., Terre T., Karstensen J., Krahmann G. 2007. MERSEA glider operation in the Mediterranean Sea, $4^{\text {th }}$ MERSEA annual meeting, April 23-24, Rome, Italy.

Tintoré J., Alvarez A., Orfila A., Balle S., Pascual A., Ruiz S., Vizoso G., Pitarch S. 2009. Department of Marine Technologies, Operational Oceanography and Sustainability: Strategic Plan 2010-2013, ISBN: 978-84-692-39-384.

Todd R., Rudnick D., Davis R., Ohman M. 2011. Underwater gliders reveal rapid arrival of El Niño effects off California's coast, Geophys. Res. Lett. 38: L03609.

Tonani M., Pinardi N., Dobricic S., Pujol I., Fratianni C. 2008. A high-resolution free-surface model of the Mediterranean Sea. Ocean Sci. 4: 1-14.

Webb D. C., Simonetti P. J., Jones C. P. 2001. SLOCUM: An underwater glider propelled by environmental energy. IEEE J. Oceanic Eng. 26: 447-452.

Received March 1, 2011. Accepted October 1, 2011.

Published online August 7, 2012. 